\title{
Potential Functional Food Ingredients in Bread and their Health Benefits
}

\author{
Muhammad Zuhair Mohd Zain ${ }^{1}$, Amal Bakr Shori ${ }^{2, *}$ (D) , Ahmad Salihin Baba ${ }^{1}$ \\ 1 Biomolecular Research Group, Division of Biochemistry, Institute of Biological Sciences, Faculty of Science, University \\ of Malaya, 50603 Kuala Lumpur, Malaysia \\ 2 King Abdulaziz University, Faculty of Science, Department of Biological Sciences, Jeddah 21589, Saudi Arabia \\ * Correspondence: shori_7506@hotmail.com (A.B.S.);
}

Scopus Author ID: 53164721600

Received: 18.06.2021; Revised: 18.09.2021; Accepted: 22.09.2021; Published: 19.11.2021

\begin{abstract}
In pace with the growing consumer health awareness and technological advances, functional foods incorporated with active ingredients are generating significant attention from researchers and consumers alike. Functional foods enriched with active ingredients provide additional health benefits beyond basic nutritional requirements. Bread has lately been used as a vehicle in the formulation of varying products. For instance, bread containing omega-3 fatty acids, whole grains bread, dietary fiber bread containing inulin, and beta-glucan. The production of functional bread has become a trend. Therefore, this review focused on health properties and potential functional food ingredients such as natural antioxidants in bread.
\end{abstract}

Keywords: bread; functional food; manufacture; health benefit; antioxidants.

(C) 2021 by the authors. This article is an open-access article distributed under the terms and conditions of the Creative Commons Attribution (CC BY) license (https://creativecommons.org/licenses/by/4.0/).

\section{Introduction}

Functional foods were first introduced in Japan in the mid-1980s [1]. These foods are fortified with healthy compounds that deliver advantages to the human body over and above the regular nutritional benefits they provide [1,2]. They have the same characteristics as ordinary foods and can be consumed in regular diets. In recent years, functional foods have grown steadily in the food industry [2].

Foods such as bread are common in the human diet and are considered functional foods. It can act as an excellent energy source. It can also be used as a carrier for nutrients such as folate, copper, thiamine, zinc, iron phytic acid, possibly minerals [3], and melanoidins [4] through fortification. In addition, bread can also serve as an eminently favorable vehicle for delivering both phenolic antioxidants and fiber polysaccharides [5]. Therefore, this review focused on health properties and potential functional food ingredients such as natural antioxidants in bread.

\section{History of Bread}

Bread is a historic dietary item that dates back to the Neolithic era, prepared by baking inside the oven. The history has been traced back to around 10,000 years BC or over 12,000 years ago where bread might have been developed by experimental mixing of water and grain flour. It is believed that Egyptians were the pioneers by making the art of bread making popular throughout the world [6]. 
Controversial fact about the history of bread is associated with political influence over public mass from the past 2000 years [6]. For example, the crisis during the cold war era has been related to white bread imperialism. The other example is the rise of the pure food movement, where it kick-started the bloom of industrial baking and scientific eating triggered by the anxiety of food-borne illness and the cleanliness of food which at that time made by workers described as unclean immigrants. This brought to the industrialization of more hygienic and mechanized production of white bread, causing a revolution between 1890 and 1930 from home-baked and small bakery bread to factory-produced bread [7].

Bread is a food produced by baking leavened dough mixed with yeast that weighs onehalf pound or more after cooling [7]. This dough might be prepared by mixing one or more ingredients such as flour, water, yeast, shortening (fatty acids), milk and/or other dairy products, egg, nutritive carbohydrate sweeteners, enzyme, lactic-acid-producing bacteria, nonwheat flours, yeast nutrients, and calcium salts, potassium bromate, calcium bromate, potassium iodate, calcium iodate and/or calcium peroxide, azodicarbonamide, dough strengtheners, spices, coloring reagent and other ingredients [7]. These ingredients need to be strictly controlled and regulated, and the bread can be called enriched bread, milk bread, raisin bread, and whole wheat bread [8]. Bread, particularly white bread, was claimed to be the highest quantity consumed since the other group of bread such as whole wheat, cracked wheat, rye, and raisin were more associated with the higher income groups [8].

Bread making process mainly implies three distinctive methods [9]. Firstly, the straight dough method by which all the ingredients are mixed at once with a different order of addition depending on manufacturer equipment and preference. Next, the sponge dough method, in which yeast, flour, and water were initially mixed before being allowed to leaven for a few hours. This is followed by the addition of the rest of the ingredients. Thirdly, the Chorleywood bread method is an ultra-high-speed mixing of all ingredients in just a few minutes [9]. In addition, the dough can be divided into lean, normal, sweet, and dietetic categories. The lean dough is basically composed of flour, water, yeast, and salt but does not contain lipid in recipes. Normal dough, on the other hand, contains a certain amount of lipid, sugar, or milk. As the name implies, the sweet dough is high in sugar, lipid, or milk, with the possible inclusion of spices, egg, or even aromatic compounds in their recipes. According to their formulation, the dietetic category can be divided into low cholesterol, low sugar, sugar-free, or fiber-enriched [9].

\section{Manufacture of Bread}

Flour and water are the most important ingredients in bread, as they mostly affect the texture and crumb. Bread dough is mainly composed of proteins, lipids, carbohydrates, water, and air. A combination of ingredients and processing conditions determines the final product's appearance, texture, microstructure, taste perception, and stability. Baking and handling processes are greatly influenced by the processing conditions (mixing, molding, sheeting, fermentation, baking) and the ingredients such as flour quality, water content, lipids added, sugar, enzymes, bran [10]. Mixing is a step to blend all the ingredients. Thus, through mixing and kneading, gluten matrix formation and incorporation of air inside dough are enhanced, converting a mixture of water and flour into viscoelastic dough [10]. During baking, the dough is converted into bread, a dramatic change whereby gas cells expand into a network of pores [10]. 
Flour consists of starch and other carbohydrates, protein, fibers, ash, lipids, water, small amounts of enzymes, vitamins, and minerals [11]. These came from wheat undergoing a milling process to produce flour that suits to produce good bread palatability, lightweight, as well as a rising loaf pattern [9]. The protein present in flour is important for the formation of gluten in bread dough. Gluten is a protein complex consisting of all amino acids, dominated by proline and glutamate or glutamine, which play an important role in gluten development [12]. Gluten is important in helping water absorption capacity, viscosity, cohesivity, and elasticity of the dough. Gluten in bread comprises two protein types, i.e., gliadins and glutenins, which can be differentiated by their solubility in aqueous alcohol. The former is soluble in aqueous alcohol, while the latter is insoluble [13]. These two protein, particularly glutenins, is important in influencing the performance of breadmaking [14]. In contact with starch, gliadin forms a viscous liquid that has no elastic force, is not sticky, and does not further develop, generating dough's viscosity. On the other hand, when glutenin is added to starch, more elastic and tenacious rubbery material is formed, providing strength and elasticity to the dough $[14,15]$.

Gluten protein also functions as a filler that fills up the space between the starch granules to build a three-dimensional network of flour particles [16]. Assemble of dough is formed by attachment of the flour particles via protein networks to one another and further extension, which can be achieved by kneading — kneading results in the extension of the protein network bidirectionally to create films. In contrast, an unextended gluten strand network comprises irregular globules that form loops and knots [16].

\section{Health Benefits of Bread}

Bread is known as a cheap source of energy (carbohydrate), protein, and to a certain extent, as a good source of fiber [8]. According to Bonafaccia et al. [11], standard cultivars of wheat flour has $13.8 \% \mathrm{dmb}$ (dry mass basis) protein, $12.8 \% \mathrm{dmb}$ dietary fiber, and the bread made from these wheat has $81.6 \% \mathrm{dmb}$ total starch and $0.9 \% \mathrm{dmb}$ free glucose.

Bread is a high glycemic index (GI) food with approximately $75 \mathrm{GI}$, which is slightly higher than rice (73 GI; [17]). A high GI value is associated with food that releases carbohydrates and increases blood glucose levels at a high rate. The health function of bread may be extended via fortification. Flour and cereals enrichment in 1953 contributed approximately one-third of thiamine supply, one-fourth of iron and niacin supply, one-fifth of food energy and protein, and one-seventh of riboflavin supply [8].

Bread can be a practical fighting tool in a weight-reducing diet. The bread (wheat product) is low in calories, but it can also be meant to help reduce body weight. Eating bread can create a feeling of fullness, helping dieters restrict calorie intake, thus causing weight loss. Eating bread also showed a significant effect in lowering blood cholesterol levels [18]. However, previous evidence revealed mixed findings of the effectiveness of a high carbohydrate diet in lowering body weight. Some might even say a high carbohydrate diet or bread intervention in a low-calorie diet did not significantly affect [19-21]. Nevertheless, bread consumption may still be an effective tool in weight loss, provided the bread consumed should be whole-grain bread, not white bread [22].

The baking of bread causes browning of bread crust due to the heating process whereby Maillard reaction between amino acids and reducing sugars leads to the formation of brown nitrogenous polymers and co-polymers named melanoidins [23-25]. Melanoidins are an important compound that acts as flavor binding to roast and sulfur aroma [26, 27]. In addition, it possesses a health effect such as metal chelator [28], antioxidants [29], exert protective effect 
over oxidative stress in the cell [30], antimicrobial [31], inhibiting effect on urease-gastric mucin (Helicobacter pylori) adhesion, thus can be a potent antibiotic that prevents of $H$. pylori adhesion [32] and induction of chemoprotective enzyme [33].

\section{Potential Functional Food Ingredients in Bread}

Functional foods have gained popularity in the last decade [1]. The increasing demand for functional food can be explained by increasing demand for a healthy lifestyle [34], increasing cost of healthcare, increase in the number of high-income people, the steady increase in life expectancy, and the desire of older people to improve and maintain their health [1]. Since bread is a common food in the daily human diet, it can be made a practical means of delivering phenolic antioxidants and fiber polysaccharides at high concentrations [5].

\subsection{Whole grain.}

Whole grains such as amaranth, buckwheat, quinoa, and rye are good sources of fiber and can be made an ingredient to incorporate in bread to deliver health benefits without abandoning flavor $[35,36]$. Buckwheat has the highest total polyphenol, followed by quinoa, wheat then amaranth. This correlates with the antioxidant activity where buckwheat has the highest. Among the four pseudocereal bread, quinoa and buckwheat seeds, and sprouts are suitable for enhancing the nutritive properties of bread, such as gluten-free bread due to potentially rich polyphenol compounds content [36]. Rye bread made with $100 \%$ rye flour was reported to be more intense in all sensory evaluation attributes except for acid odor, acid taste, and salty taste and showed higher total polyphenol content than wholemeal flour but lower DPPH scavenging activity [37].

\subsection{Soybean and sweet potato.}

Phytochemicals are one of the bioactive ingredients that are found naturally in plants and fruit. Soybean has rich in antioxidant activity $[38,39]$ and moderate anti-inflammatory effect [40]. The incorporation of soybean into bread may increase the level of protein, dough water absorption, and ash content. However, incorporation did affect the organoleptic properties of bread, decreased bread volume, and darker crumb [41, 42]. Sweet potato flour substitution was shown to increase bread's antioxidant activity, and fortification can be made until $20 \%$ of total flour with an insignificant difference in terms of aroma, taste, and texture. However, the substitution produced harder and darker crust [43].

\subsection{Green tea.}

Green tea is a good source of polyphenol and caffeine [44]. Incorporation of green tea into bread showed an increase in hardness, stickiness, and astringency, whereas lower brightness and sweetness when increasing the amount of green tea extract inclusion [45]. However, this problem might be countered through green tea encapsulation [46].

\subsection{Herbs and spices.}

Coriander leaves and seeds are some of the widely used herbs in food as spice or flavor enhancers. Roasted coriander seeds are even used in beverages and medicinal preparations. The effect of heating or roasting does not seem to alter its bioactive content, and the seed also 
exhibited strong antioxidant and anti-inflammatory activities [47]. The addition of coriander leaves in bread at $3.0 \%$ and $5.0 \%(\mathrm{w} / \mathrm{w})$ replacement of wheat flour [48] improved bread characteristics such as texture, color, and flavor of the bread as well as increased antioxidant activity, slower staling rate, increased moisture content and decreased crumb firmness.

Turmeric (Curcuma longa L.) phenolic curcumin (diferuoyl methane) was reported to possess antioxidant, anti-protozoal, anti-tumor, anti-inflammatory, and anti-venom activities [49]. The addition of turmeric powder in bread results in higher phenolic content, antioxidant activity, and shelf-life of bread than normal wheat bread. In addition, the acceptable sensory scores were reported at $4 \%$ substitution turmeric powder of wheat flour. However, increasing turmeric powder supplementation increased its hardness and crumb color (stronger yellow color; [50]).

Ginger (Zingiber officinale Roscoe) is a popular herb used in Asia, where its leaves, stem, and rhizome possess phenolic content and antioxidant activity [51]. The addition of ginger powder into bread increase the hardness and gumminess of bread crumb, forming a darker brown-colored crumb and increasing antioxidants and phenolic content. The acceptable supplementation was at 3\% substitution of wheat flour due to good rheological characteristics and highest sensorial acceptability rating, which exhibit twice higher antioxidant content than control bread [52].

\subsection{Fruits and fruit wastes.}

The addition of grape seed extract to bread showed higher antioxidant activity compared to blank bread [53]. However, the heating process during breadmaking decreased the antioxidant of grape seed extract by around 30-40\%. Grape seed extract may also potentially reduce $\mathrm{N} \varepsilon$-(carboxymethyl)lysine (CML) formation, which is a potential toxicant in bread, thus producing bread with lower CML-related health risks [53].

Fennel (Foeniculum vulgare var. dulce) seeds are a type of herb which is a good source of sugars, essential fatty acids, vital vitamins, minerals, protein, fiber, essential oil, and flavonoid [54]. Due to its sweet-smelling property, fennel seeds are widely used in the therapeutic and culinary areas. Supplementation of fennel seeds powder in bread is likely accepted than other fortified bread [54]. The increasing proportion of fennel increases crumb firmness, crumb moisture, and antioxidant content, with the optimum addition being between 5.0 and $7.0 \%$ [54].

Apart from dietary sources, agriculture byproducts of food processing industries such as the peels and seeds of many fruits can be potential sources of antioxidants [55]. Supplementation of dried apple skin powder into muffins showed an increment in total dietary fiber, total phenolic content, and antioxidant activity. Therefore, the use of apple skin in bakery products can be considered a source of natural antioxidants [56].

The addition of watermelon rinds and sharlyn melon peels to the cake has increased fiber, carbohydrates, moisture, and potentially good antioxidant activity source to increase the shelf-life of the cake. The recommended addition is at 5\% substitution of wheat flour [57].

Mango peel powder may be added to biscuits to increase total dietary fiber, polyphenols, carotenoid content, and antioxidant activity. The acceptable addition of mango peel powder is at $10 \%$ substitution of wheat flour [58].

\subsection{Green coffee bean.}


Supplementation of green coffee bean extract into bread and sponge cake increased the antioxidant activities [59]. However, the addition caused significant changes in the sensory properties since an increasing amount of green coffee beans resulted in a change in the color of sponge cake and bread [59]. In addition, green coffee bean bread showed that the phenolic content is potentially highly bioaccessible and bioavailable due to its highly masticationextractable property. The supplemented bread phenolics content and antioxidant activity are correlated with powdered green coffee bean added. The acceptable supplementation is at $3 \%$ substitution of wheat flour to give the satisfactory overall consumer acceptability [60].

\subsection{Other potential ingredients.}

Supplementation of beta carotene taken from oil to whole wheat bread showed a significant loss during baking [61]. However, in the presence of antioxidants, wheat bread exhibited more stability throughout baking, although not during storage $\left(25^{\circ} \mathrm{C}\right)$. Bread supplemented with beta carotene can be known as a good source of vitamin A, and the more carotene added, the higher carotene available in bread [61]. In addition, the phenolic acid has been supplemented into the bread. Caffeic acid showed the highest antioxidant activity before and after baking, followed by ferulic acid, gallic acid, and syringic acid. Although there is a significant effect of baking towards the degradation of phenolic acid, the recovery after baking is still high ranging from $74-80 \%$ [62].

\section{Conclusions}

The consumer demands for health-giving food products and awareness of a healthy lifestyle based on consumption of functional foods are growing. Bakers also seek natural ingredients and enzymes to replace chemically produced ones, inhibitors to delay mold growth and extend shelf life, and specialty proteins to improve dough handling. Recently, natural antioxidants from the plants have played an important role in functional foods, i.e., inhibiting lipid peroxidation in food and improving quality in terms of appearance, taste, and texture. Therefore, incorporating natural phenolic antioxidants from plants in bread could enhance human health performance and control the body suffering from degenerative diseases associated with today's changing lifestyles and the environment.

\section{Funding}

This research received no external funding.

\section{Acknowledgments}

This research has no acknowledgments.

\section{Conflicts of Interest}

The authors declare no conflict of interest.

\section{References}

1. Guiné, R.P.; Florença, S.G.; Barroca, M.J.; Anjos, O. The link between the consumer and the innovations in food product development. Foods 2020, 9, 1317, https://doi.org/10.3390/foods9091317. 
2. Granato, D.; Barba, F.J.; Bursać Kovačević, D.; Lorenzo, J.M.; Cruz, A.G.; Putnik, P. Functional foods: Product development, technological trends, efficacy testing, and safety. Annual review of food science and technology 2020, 11, 93-118, https://doi.org/10.1146/annurev-food-032519-051708.

3. Helou, C.; Gadonna-Widehem, P.; Robert, N.; Branlard, G.; Thebault, J.; Librere, S.; Jacquot, S.; Mardon, J.; Piquet-Pissaloux, A.; Chapron, S.; Chatillon, A. The impact of raw materials and baking conditions on Maillard reaction products, thiamine, folate, phytic acid and minerals in white bread. Food \& function 2016, 7, 2498-2507, https://doi.org/10.1039/c5fo01341k.

4. Helou, C.; Jacolot, P.; Niquet-Léridon, C.; Gadonna-Widehem, P.; Tessier, F.J. Maillard reaction products in bread: A novel semi-quantitative method for evaluating melanoidins in bread. Food Chemistry 2016, 190, 904-911, https://doi.org/10.1016/j.foodchem.2015.06.032.

5. Shori, A.B.; Kee, L.A.; Baba, A.S. Total Phenols, Antioxidant Activity and Sensory Evaluation of Bread Fortified with Spearmint. Arabian Journal for Science and Engineering 2021, 46, 5257-5264, https://doi.org/10.1007/s13369-020-05012-5.

6. Bredariol, P.; Vanin, F.M. Bread baking Review: Insight into Technological Aspects in order to Preserve Nutrition. Food Reviews International 2021, 1-18, https://doi.org/10.1080/87559129.2021.1878211.

7. Defraeye, P. White Bread. TranscUlturAl: A Journal of Translation and Cultural Studies 2016, 8, 101-105, https://doi.org/10.21992/T9JH0D.

8. Gębski, J.; Jezewska-Zychowicz, M.; Szlachciuk, J.; Kosicka-Gębska, M. Impact of nutritional claims on consumer preferences for bread with varied fiber and salt content. Food Quality and Preference 2019, 76, 91-99, https://doi.org/10.1016/J.FOODQUAL.2019.03.012.

9. Krasnikova, E.S.; Krasnikov, A.V.; Babushkin, V.A. The influence of composite flour mixtures on saccharomyces cerevisiae biotechnological properties and bread quality. In IOP Conference Series: Earth and Environmental Science 2020, 421, 022008, https://doi.org/10.1088/1755-1315/421/2/022008.

10. Mitreva, E.; Gjurevska, S.; Gjorshevski, H. Optimization of the business processes in a company for manufacture of bread and bakery products in Macedonia. Tem Journal 2018, 7, 439-445, https://doi.org/10.18421/TEM72-28.

11. Bonafaccia, G.; Galli, V.; Francisci, R.; Mair, V.; Skrabanja, V.; Kreft, I. Characteristics of spelt wheat products and nutritional value of spelt wheat-based bread. Food Chemistry 2000, 68, 437-441, https://doi.org/10.1016/S0308-8146(99)00215-0.

12. Verbauwhede, A.E.; Lambrecht, M.A.; Fierens, E.; Shegay, O.; Brijs, K.; Delcour, J.A. Impact of aqualysin 1 peptidase from Thermus aquaticus on molecular scale changes in the wheat gluten network during bread baking. Food chemistry 2019, 295, 599-606, https://doi.org/10.1016/j.foodchem.2019.05.161.

13. Lammers, K.M.; Herrera, M.G.; Dodero, V.I. Translational Chemistry Meets Gluten-Related Disorders. ChemistryOpen 2018, 7, 217-232, https://doi.org/10.1002/open.201700197.

14. Ahmed, J.; Thomas, L.; Al-Hazza, A. Effects of frozen storage on texture, microstructure, water mobility and baking quality of brown wheat flour//-glucan concentrate Arabic bread dough. Journal of Food Measurement and Characterization 2021, 15, 1258-1269, https://doi.org//10.1007/s11694-020-00725-5.

15. Nawrocka, A.; Szymańska-Chargot, M.; Miś, A.; Wilczewska, A.Z.; Markiewicz, K.H. Effect of dietary fibre polysaccharides on structure and thermal properties of gluten proteins-A study on gluten dough with application of FT-Raman spectroscopy, TGA and DSC. Food Hydrocolloids 2017, 69, 410-421, https://doi.org/10.1016/j.foodhyd.2017.03.012.

16. Nawrocka, A.; Szymańska-Chargot, M.; Miś, A.; Wilczewska, A.Z.; Markiewicz, K.H. Aggregation of gluten proteins in model dough after fibre polysaccharide addition. Food chemistry 2017, 231, 51-60, https://doi.org/10.1016/j.foodchem.2017.03.117.

17. Rytz, A.; Adeline, D.; Lê, K.A.; Tan, D.; Lamothe, L.; Roger, O.; Macé, K. Predicting Glycemic Index and Glycemic Load from Macronutrients to Accelerate Development of Foods and Beverages with Lower Glucose Responses. Nutrients 2019, 11, 1172, https://doi.org/10.3390/nu11051172.

18. Sakr, N.; Rhazi, L.; Aussenac, T. Bread wheat quality under limiting environmental conditions: I-Molecular properties of storage proteins and starch constituents in mature grains. Agriculture 2021, 11, 289, https://doi.org/10.3390/agriculture11040289.

19. Ebbeling, C.B.; Feldman, H.A.; Klein, G.L.; Wong, J.M.; Bielak, L.; Steltz, S.K.; Luoto, P.K.; Wolfe, R.R.; Wong, W.W.; Ludwig, D.S. Effects of a low carbohydrate diet on energy expenditure during weight loss maintenance: randomized trial. Bmj 2018, 363, https://doi.org/10.1136/bmj.k4583. 
20. McAuley, K.A.; Hopkins, C.M.; Smith, K.J.; McLay, R.T.; Williams, S.M.; Taylor, R.W.; Mann, J.I. Comparison of high-fat and high-protein diets with a high-carbohydrate diet in insulin-resistant obese women. Diabetologia 2005, 48, 8-16, https://doi.org/10.1007/s00125-004-1603-4.

21. Loria-Kohen, V.; Gómez-Candela, C.; Fernández-Fernández, C.; Pérez-Torres, A.; García-Puig, J.; Bermejo, L.M. Evaluation of the usefulness of a low-calorie diet with or without bread in the treatment of overweight/obesity. Clinical Nutrition 2012, 31, 455-461, https://doi.org/10.1016/j.clnu.2011.12.002.

22. Serra-Majem, L.; Bautista-Castaño, I. Relationship between bread and obesity. British Journal of Nutrition 2015, 113, S29-S35, https://doi.org/10.1017/S0007114514003249.

23. Nooshkam, M.; Varidi, M.; Bashash, M. The Maillard reaction products as food-born antioxidant and antibrowning agents in model and real food systems. Food chemistry 2019, 275, 644-660, https://doi.org/10.1016/j.foodchem.2018.09.083.

24. Hemmler, D.; Roullier-Gall, C.; Marshall, J.W.; Rychlik, M.; Taylor, A.J.; Schmitt-Kopplin, P. Insights into the chemistry of non-enzymatic browning reactions in different ribose-amino acid model systems. Scientific reports 2018, 8, 1-10, https://doi.org/10.1038/s41598-018-34335-5.

25. Li, D.; Xie, Y.; Na, X.; Li, Y.; Dai, C.; Li, Y.; Tan, M. Insights into melanoidin conversion into fluorescent nanoparticles in the Maillard reaction. Food \& function 2019, 10, 4414-4422, https://doi.org/10.1039/C9FO00383E.

26. Laukalēja, I.; Krūma, Z. Quality of specialty coffee: balance between aroma, flavour and biologically active compound composition. Research Ror Rul Development 2018, 1, https://doi.org/10.22616/rrd.24.2018.038.

27. Starowicz, M.; Zieliński, H. How maillard reaction influences sensorial properties (color, flavor and texture) of food products. Food Reviews International $\quad \mathbf{2 0 1 9}, 35, \quad$ 707-725, https://doi.org/10.1080/87559129.2019.1600538.

28. Oracz, J.; Zyzelewicz, D. In vitro antioxidant activity and FTIR characterization of high-molecular weight melanoidin fractions from different types of cocoa beans. Antioxidants 2019, 8, 560, https://doi.org/10.3390/antiox8110560.

29. Shen, Y.; Chen, G.; Li, Y. Bread characteristics and antioxidant activities of Maillard reaction products of white pan bread containing various sugars. $L W T \quad \mathbf{2 0 1 8}, 95, \quad 308-315$, https://doi.org/10.1016/j.lwt.2018.05.008.

30. Mesías, M.; Delgado-Andrade, C. Melanoidins as a potential functional food ingredient. Current Opinion in Food Science 2017, 14, 37-42, https://doi.org/10.1016/j.cofs.2017.01.007.

31. Wu, S.; Dai, X.; Shilong, F.; Zhu, M.; Shen, X.; Zhang, K.; Li, S. Antimicrobial and antioxidant capacity of glucosamine-zinc (II) complex via non-enzymatic browning reaction. Food science and biotechnology 2018, 27, 1-7, https://doi.org/10.1007/s10068-017-0192-1.

32. Hiramoto, S.; Itoh, K.; Shizuuchi, S.; Kawachi, Y.; Morishita, Y.; Nagase, M.; Suzuki, Y.; Nobuta, Y.; Sudou, Y.; Nakamura, O.; Kagaya, I. Melanoidin, a food protein-derived advanced Maillard reaction product, suppresses Helicobacter pylori in vitro and in vivo. Helicobacter 2004, 9, 429-435, https://doi.org/10.1111/j.1083-4389.2004.00263.x.

33. Shen, Y.; Chen, G.; Li, Y. Bread characteristics and antioxidant activities of Maillard reaction products of white pan bread containing various sugars. $L W T$ 2018, 95, 308-315, https://doi.org/10.1016/j.lwt.2018.05.008.

34. Gok, I.; Ulu, E.K. Functional foods in Turkey: marketing, consumer awareness and regulatory aspects. Nutrition \& Food Science 2019, https://doi.org/10.1108/NFS-07-2018-0198.

35. Arslan-Tontul, S., Uslu, C. C., Mutlu, C., \& Erbaş, M. Expected glycemic impact and probiotic stimulating effects of whole grain flours of buckwheat, quinoa, amaranth and chia. Journal of Food Science and Technology 2021, 1-8, https://doi.org/10.1007/s13197-021-05156-8.

36. Alvarez-Jubete, L.; Wijngaard, H.; Arendt, E.K.; Gallagher, E. Polyphenol composition and in vitro antioxidant activity of amaranth, quinoa buckwheat and wheat as affected by sprouting and baking. Food chemistry 2010, 119, 770-778, https://doi.org/10.1016/j.foodchem.2009.07.032.

37. Cyran, M.R.; Dynkowska, W.M.; Ceglińska, A.; Bonikowski, R. Improving rye bread antioxidant capacity by breadmaking methodology: Contribution of phosphate-buffered saline-and methanol-soluble phenolic phytochemicals with different molecular profiles. Journal of Cereal Science 2021, 103262, https://doi.org/10.1016/j.jcs.2021.103262.

38. Zhang, B.; Yang, Z.; Huang, W.; Omedi, J.O.; Wang, F.; Zou, Q.; Zheng, J. Isoflavone aglycones enrichment in soybean sourdough bread fermented by lactic acid bacteria strains isolated from traditional Qu starters: 
Effects on in vitro gastrointestinal digestion, nutritional, and baking properties. Cereal Chemistry 2019, 96, 129-141, https://doi.org/10.1002/cche.10116.

39. Milani, J.M.; Sedighi, N.; Mirzaei, H. Effect of germinated and non germinated soybean flour on quality of Barbari bread. Electronic Journal of Food Processing and Preservation 2018, 10, 73-84, https://doi.org/0.22069/EJFPP.2018.10294.1315.

40. Ahn-Jarvis, J.; Lombardo, E.; Cruz-Monserrate, Z.; Badi, N.; Crowe, O.; Kaul, S.; Komar, H.; Krishna, S.G.; Lesinski, G.B.; Mace, T.A.; Ramsey, M.L. Reduction of inflammation in chronic pancreatitis using a soy $\begin{array}{lllll}\text { bread intervention: A feasibility study. Pancreatology } & \mathbf{2 0 2 0}, 20, & 852-859 \text {, }\end{array}$ https://doi.org/10.1016/j.pan.2020.04.018.

41. Ayele, H.H.; Bultosa, G.; Abera, T.; Astatkie, T. Nutritional and sensory quality of wheat bread supplemented with cassava and soybean flours. Cogent Food \& Agriculture 2017, 3, 1331892 , https://doi.org/10.1080/23311932.2017.1331892.

42. Tavan, Z.; Hojjati, M.; Nasehi, B.; Jooyandeh, H. Effect of sesame meal and soluble soybean polysaccharide on properties of Barbary bread. Iranian Journal of Biosystems Engineering 2017, 48, 333-342, https://doi.org/10.22059/IJBSE.2017.62475.

43. Mau, J.L.; Lee, C.C.; Yang, C.W.; Chen, R.W.; Zhang, Q.F.; Lin, S.D. Physicochemical, antioxidant and sensory characteristics of bread partially substituted with aerial parts of sweet potato. LWT 2020, 117, 108602, https://doi.org/10.1016/j.lwt.2019.108602.

44. Shori, A.B.; Muniandy, P.; Baba, A.S. Changes in Phenolic Compounds Profiles in Tea Extracts and the Composition of these Phenolic Compounds in Yogurt. Recent Patents on Food, Nutrition \& Agriculture 2021, 12, 36-44, https://doi.org/10.2174/2212798411999201123205022.

45. Ning, J.; Hou, G.G.; Sun, J.; Wan, X.; Dubat, A. Effect of green tea powder on the quality attributes and antioxidant activity of whole-wheat flour pan bread. LWT-Food Science and Technology 2017, 79, 342-348, https://doi.org/10.1016/j.lwt.2017.01.052.

46. Gómez-Mascaraque, L.G.; Hernández-Rojas, M.; Tarancón, P.; Tenon, M.; Feuillère, N.; Ruiz, J.F.V.; Fiszman, S.; López-Rubio, A. Impact of microencapsulation within electrosprayed proteins on the formulation of green tea extract-enriched biscuits. LWT-Food Science and Technology 2017, 81, 77-86, https://doi.org/10.1016/j.lwt.2017.03.041.

47. Shori, A.B. Proteolytic activity, antioxidant, and $\alpha$-Amylase inhibitory activity of yogurt enriched with coriander and cumin seeds. LWT 2020, 133, 109912, https://doi.org/10.1016/j.lwt.2020.109912.

48. Das, L.; Raychaudhuri, U.; Chakraborty, R. Supplementation of common white bread by coriander leaf powder. Food Science and Biotechnology 2012, 21, 425-433, https://doi.org/10.1007/s10068-012-0054-9.

49. Gómez-Estaca, J.; Balaguer, M.P.; López-Carballo, G.; Gavara, R.; Hernández-Muñoz, P. Improving antioxidant and antimicrobial properties of curcumin by means of encapsulation in gelatin through electrohydrodynamic $\quad$ atomization. Food $\quad$ Hydrocolloids $\quad \mathbf{2 0 1 7}, \mathbf{7 0 ,}$ 313-320, https://doi.org/10.1016/j.foodhyd.2017.04.019.

50. Lim, H.S.; Park, S.H.; Ghafoor, K.; Hwang, S.Y.; Park, J. Quality and antioxidant properties of bread containing turmeric (Curcuma longa L.) cultivated in South Korea. Food Chemistry 2011, 124,1577-1582, https://doi.org/10.1016/j.foodchem.2010.08.016.

51. Shori, A.B. Inclusion of phenolic compounds from different medicinal plants to increase $\alpha$-amylase inhibition activity and antioxidants in yogurt. Journal of Taibah University for Science 2020, 14, 1000-1008, https://doi.org/10.1080/16583655.2020.1798072.

52. Balestra, F.; Cocci, E.,; Pinnavaia, G.; Romani, S. Evaluation of antioxidant, rheological and sensorial properties of wheat flour dough and bread containing ginger powder. LWT-Food Science and Technology 2011, 44, 700-705, https://doi.org/10.1016/j.lwt.2010.10.017.

53. Peng, X.; Ma, J.; Cheng, K.W.; Jiang, Y.; Chen, F.; Wang, M. The effects of grape seed extract fortification on the antioxidant activity and quality attributes of bread. Food Chemistry 2010, 119, 49-53, https://doi.org/10.1016/j.foodchem.2009.05.083.

54. Das, L.; Raychaudhuri, U.; Chakraborty, R. Herbal fortification of bread with fennel seeds. Food Technology and Biotechnology 2013, 51, 434.

55. Ibrahim, U.K.; Kamarrudin, N.; Suzihaque, M.U.H.; Abd Hashib, S. Local fruit wastes as a potential source of natural antioxidant: an overview. In IOP conference series: materials science and engineering 2017, 206, 012040, https://doi.org/10.1088/1757-899X/206/1/012040. 
56. Rupasinghe, H.V.; Wang, L.; Huber, G.M.; Pitts, N.L. Effect of baking on dietary fibre and phenolics of muffins incorporated with apple skin powder. Food Chemistry 2008, 107, 1217-1224, https://doi.org/10.1016/j.foodchem.2007.09.057.

57. Al-Sayed, H.M.; Ahmed, A.R. Utilization of watermelon rinds and sharlyn melon peels as a natural source of dietary fiber and antioxidants in cake. Annals of Agricultural Sciences 2013,58, 83-95, https://doi.org/10.1016/j.aoas.2013.01.012.

58. Salehi, F. Recent applications of powdered fruits and vegetables as novel ingredients in biscuits: a review. Nutrire 2020, 45, 1-10, https://doi.org/10.1186/s41110-019-0103-8.

59. Zain, M.Z.M.; Baba, A.S.; Shori, A.B. Effect of polyphenols enriched from green coffee bean on antioxidant activity and sensory evaluation of bread. Journal of King Saud University-Science 2018, 30, 278-282, https://doi.org/10.1016/j.jksus.2017.12.003.

60. Dziki, D.; Gawlik-Dziki, U.; Pecio, Ł.; Różyło, R.; Świeca, M.; Krzykowski, A.; Rudy, S. Ground green coffee beans as a functional food supplement-Preliminary study. LWT-Food Science and Technology 2015, 63, 691-699, https://doi.org/10.1016/j.lwt.2015.03.076.

61. Ranhotra, G.S.; Gelroth, J.A.; Langemeier, J.; Rogers, D.E. Stability and contribution of beta carotene added to whole wheat bread and crackers. Cereal chemistry 1995, 72, 139-141.

62. Han, H.M.; Koh, B.K. Antioxidant activity of hard wheat flour, dough and bread prepared using various processes with the addition of different phenolic acids. Journal of the Science of Food and Agriculture 2011, 91, 604-608, https://doi.org/10.1002/jsfa.4188. 